\title{
Combined quality of life and posttraumatic growth evaluation during follow-up care of patients suffering from oral squamous cell carcinoma
}

\author{
GEORG HOENE $^{1 *}$, RUDOLF M. GRUBER ${ }^{1 *}$, JOHANNA J. LEONHARD ${ }^{1}$, BERNHARD WIECHENS ${ }^{2}$, \\ BORIS SCHMINKE ${ }^{1}$, PHILIPP KAUFFMANN ${ }^{1}$, HENNING SCHLIEPHAKE ${ }^{1}$ and PHILLIPP BROCKMEYER ${ }^{1}$ \\ Departments of ${ }^{1}$ Oral and Maxillofacial Surgery and ${ }^{2}$ Orthodontics, \\ University Medical Center Goettingen, Goettingen D-37575, Germany
}

Received March 26, 2021; Accepted June 11, 2021

DOI: $10.3892 / \mathrm{mco} .2021 .2351$

\begin{abstract}
Oral cancer therapy is associated with a loss in health-related quality of life (HRQOL) and can also lead to post-traumatic growth (PTG). The current study analyzed the relationship between HRQOL, PTG and influencing clinical factors after treatment. The coherent clinical data of 15 patients were retrospectively analyzed over a 1-year study period. HRQOL and PTG were studied using the University of Washington Quality of Life Version 4 (UW-QOL v4) and Posttraumatic Growth Inventory (PTGI) questionnaires. The results revealed that $\mathrm{HRQOL}$ was significantly decreased in a pre- to postoperative manner $(\mathrm{P}=0.011)$. Sex demonstrated a nearly significant effect on HRQOL $(\mathrm{P}=0.058)$. PTG was experienced the most after surgery, and continuously decreased over the 1-year study period. Patient age had a significant effect on PTG $(\mathrm{P}=0.040)$. A significant correlation was also established between HRQOL and PTG $(\mathrm{P}<0.05)$. HRQOL and PTG are important influencing factors during postoperative tumor follow-up care and should be simultaneously recorded to address individual patient needs and improve quality of treatment.
\end{abstract}

\section{Introduction}

Tumors of the head and neck region are a heterogeneous group of neoplasms and are among the most common cancer worldwide (1). With a proportion of $90 \%$, squamous cell carcinoma (SCC) is the most common histological type $(2,3)$.

Correspondence to: Dr Phillipp Brockmeyer, Department of Oral and Maxillofacial Surgery, University Medical Center Goettingen, Robert-Koch-Street 40, D-37575 Goettingen, Germany

E-mail: ph.brockmeyer@gmail.com

*Contributed equally

Key words: oral squamous cell carcinoma, oral squamous cell carcinoma, health-related quality of life, posttraumatic growth, tumor outcome
The main risk factors for the development of oral squamous cell carcinoma (OSCC) are chronic alcohol and/or nicotine abuse with synergistic potentiation (4). Surgical therapy for extensive OSCC is associated with a functional loss in stomatology, aesthetic restrictions, and a deterioration in a patient's health-related quality of life (HRQOL). HRQOL evaluation is a multidimensional concept comprising positive and negative components (5-7). Besides physical, psychological, and social dimensions, marital status and spiritual well-being are also important influencing factors $(8,9)$. Various questionnaires have been developed to assess HRQOL in different dimensions (10-13). Among them, the University of Washington Quality of Life Questionnaire version 4 (UW-QoL V4) is a widely used tool for HRQOL evaluation in patients with OSCC (14), and is routinely used in many centers worldwide during postoperative follow-up care.

Cancer diagnosis and treatment are traumatic life events that can trigger post-traumatic stress disorder (PTSD) $(15,16)$, but can also lead to subjectively positive effects, such as post-traumatic growth (PTG) $(17,18)$. PTG does not refer to the traumatic event itself, but the subjectively perceived positive change in the way in which the traumatic experience is dealt with (17). Many sociodemographic factors, such as age, sex, social support, religion, educational level, income, resilience, HRQOL, and disease severity, have been discussed to affect PTG. PTG can be assessed using the PTG-inventory (PTGI) questionnaire developed by R. Tedeschi and L. Calhoun (19).

Both HRQOL and PTG are important influencing factors during post-therapy cancer follow-up care. For this reason, a better understanding of the relationships between HRQOL, PTG, and influencing clinical factors is important in specifically addressing individual patient needs and improving quality of treatment. To the authors' knowledge, this study is the first to report a combined HRQOL and PTG evaluation in patients with OSCC.

\section{Materials and methods}

Patients and data acquisition. Coherent clinical data (seamless data acquisition over the entire observation period) of 15 patients with OSCC mainly treated surgically between January 2011 
and June 2012 were retrospectively analyzed. Data included patient characteristics, such as age, sex, marital status, and denominational affiliation; pathological characteristics, such as localization of the primary tumor and TNM classification; and therapy characteristics, such as surgical reconstruction modality and adjuvant therapy. Clinical data of patients can be found in Table I. HRQOL and PTG were recorded using the UW-QoL V4 and PTGI questionnaires $(14,19,20)$. UW-QoL V4 was completed one day preoperatively and during postoperative tumor follow-ups (after 1/2, 1, 3, 6, 9, and 12 months); and it consisted of 12 questions concerning the domains of pain, appearance, activity, recreation, swallowing, chewing, speech, shoulder function, taste, saliva, mood, and anxiety. PTGI was completed after 1, 6, and 12 months postoperatively; and it consisted of 21 questions with six possible answers to evaluate the five subscales ['relating to others' ( $R O)$, 'new possibilities' $(N P)$, 'personal strength' $(P S)$, 'appreciation of life' $(A O L)$, and 'spiritual change' $(S C)$ ]. Of the 30 patients with OSCC who initially agreed to participate in the trial, 15 completed all questionnaires $(n=15)$ over the one-year study period and were included in the final statistical evaluation (attrition rate, $\mathrm{n}=15$ ).

Statistical evaluation. All HRQOL and PTG subscales were analyzed using a Friedman test. Significant test scores were further examined with a pairwise comparison using the Bonferroni-Dunn post hoc test. To investigate all possible influencing factors (e.g., sex, age, religious denomination, and marital status) on PTG, further correlation tests were performed. Mann-Whitney U tests for independent samples, and Wilcoxon tests for paired samples, were used to compare two groups. In addition, a descriptive statistical evaluation of pre- and postoperative HRQOL, as well as presentation of the different influencing variables on HRQOL, was performed. A Spearman's correlation analysis was performed to describe the relationship of HRQOL and PTG. All analyses were performed using SAS 9.4-(SAS Institute, Inc), Statistica 10.0 (Hamburg, Germany) and SPSS 24 (IBM; SPSS, Inc.) software. All tests resulting in a $\mathrm{P}$-value $<0.05$ were considered statistically significant.

\section{Results}

Health-related quality of life (HRQOL). HRQOL evaluation revealed that both physical and socio-emotional HRQOL decreased in a pre- to-postoperative manner in all patients (Fig. 1A and B).

The mean UW-QoL v4 value in the physical function increased from 11 points preoperatively to 25 points postoperatively, indicating a decrease in physical HRQOL. In the area of physical function score, swallowing (MV,

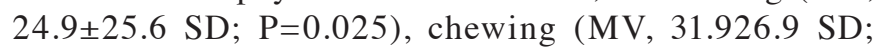
$\mathrm{P}=0.002)$ and speech $(\mathrm{MV}, 19.1 \pm 20.7 \mathrm{SD} ; \mathrm{P}=0.016)$ were the main factors responsible for postoperative deterioration in HRQOL. The mean value of the socio-emotional function increased from the preoperative (21 points) to postoperative (28 points) stage. Socio-emotional HRQOL was strongly influenced by patients' shoulder function (MV, 15.1 23.0 ; $\mathrm{P}<0.0001$ ), and mood (mean, 32.4 \pm 25.2 ) which showed high mean values over the entire study period and was only subject to a few fluctuations. This result, however, was not statistically significant $(\mathrm{P}=0.88)$.

Statistical analysis of the preoperative UW-QoL v4 data with the one-year postoperative data indicated a significant decrease in the physical $(\mathrm{P}=0.011 ; 11$ points preop, 23 points after 1 year) but not in the socio-emotional HRQOL $(\mathrm{P}=0.972$; 21 points preop, 22 points after 1 year) over the one-year study period.

Correlation analysis results between various clinical baseline characteristics and the physical and socio-emotional HRQOL revealed that sex had a nearly significant effect on HRQOL $(\mathrm{P}=0.058)$. In general, men indicated a poorer HRQOL than women. On average, single patients reported a slightly poorer overall HRQOL than married patients. However, this difference was not significant $(\mathrm{P}=0.113)$. Furthermore, no significant effect of denominational affiliation $(\mathrm{P}=0.908)$ and patient's age $(\mathrm{P}=0.261)$ on HRQOL could be observed.

On average, patients with tumors classified as T1/T2, free microvascular flap reconstruction, and no additional radiotherapy (RT) were characterized by the poorest HRQOL scores. Patients (T1/T2) who received local defect reconstruction reported a better HRQOL. In T1/T2 carcinomas, socio-emotional HRQOL was rated as worse than physical HRQOL, regardless of the type of therapy used. In patients without free microvascular flap reconstruction and RT, no major difference could be observed between physical and socio-emotional HRQOL. In general, patients with T3/T4 carcinomas rated their physical HRQOL worse than those of other groups.

Post-traumatic growth (PTG). For PTG evaluation, three postoperative questionnaires $(1,6$, and 12 months postoperative) were available for each patient. Mean PTG values per question (MV) for all patients are shown in Fig. 2A. The five subscales: 'Relating to others' (RO), 'new possibilities' (NP), 'personal strength' (PS), 'appreciation of life' (AOL), and 'spiritual change' (SC), composed of different number of questions, were separately evaluated. The mean values were used for comparison. The mean overall PTG score was 72.2 \pm 35.7 (95\% CI, 69.9-74.5).

Results show that patients most strongly felt PTG shortly after surgery (1 month postoperatively). Mean values of all subscales revealed a PTG decrease over the study period, which was also observed uniformly for all subscales. The biggest changes were found in 'appreciation of life' (MV, $4.1 \pm 1.8$; 95\% CI, 3.6-4.6) and 'relating to others' (MV, 3.9 \pm 1.5 ; 95\% CI, 3.5-4.3). 'Personal strength' (MV, 3.3 \pm 1.6 ; 95\% CI, 2.8-3.8) and 'new possibilities' (MV, 3.0 \pm 1.6 ; 95\% CI, 2.5-3.5) values slightly decreased in comparison. The lowest values were found in the 'spiritual change' subscale (MV, 2.2 \pm 2.7 ; 95\% CI, 1.4-3.0). 'Appreciation of life' showed the highest decrease over all three timepoints ( 1 to 12 months postoperatively). Initially, a moderate decrease (MV, 4.8 to 4.4) from 1 to 6 months postoperatively was found, whereas a strong decrease from 6 months to 12 months postoperatively (MV 4.4 to MV 3.2) was observed. Additionally, for 'new possibilities' and 'personal strength,' such decrease was, however, found with initial lower values (NP MV 3.4 to MV 2.5; PS MV 3.8 to MV.8). 'Relating to others' showed a strong decrease from 
Table I. Patient clinical characteristics.

\begin{tabular}{|c|c|c|c|c|c|c|c|c|c|}
\hline Sex & Age & Profession & Religion & $\begin{array}{c}\text { Marital } \\
\text { status }\end{array}$ & Tumor localization & pT & $\mathrm{pN}$ & $\mathrm{pM}$ & Reconstruction \\
\hline Male & 48 & Gardener & None & Not married & Anterior mouth floor & 4 & 2 & 0 & Distant flap \\
\hline Female & 48 & Psychotherapist & Evangelic & Divorced & $\begin{array}{l}\text { Lateral upper } \\
\text { alveolar process }\end{array}$ & 2 & 0 & 0 & Local \\
\hline Male & 67 & Baker & Catholic & Not married & Lateral mouth floor & 1 & 0 & 0 & Local \\
\hline Male & 47 & $\begin{array}{l}\text { Warehouse } \\
\text { worker }\end{array}$ & Muslim & Not married & Cheek & 1 & 0 & 0 & Distant flap \\
\hline Female & 94 & Secretary & Evangelic & Widowed & Lateral tongue & Cis & 0 & 0 & Local \\
\hline Male & 48 & Educator & Catholic & Not married & Palate & 1 & 0 & 0 & Local \\
\hline Male & 67 & Manager & Evangelic & Married & Anterior mouth floor & 2 & 0 & 0 & Distant flap \\
\hline Male & 63 & Caregiver & Catholic & Married & $\begin{array}{l}\text { Lateral lower } \\
\text { alveolar process }\end{array}$ & 4 & 0 & 0 & Distant flap \\
\hline Male & 64 & Caregiver & Catholic & Married & $\begin{array}{l}\text { Lateral lower } \\
\text { alveolar process }\end{array}$ & 4 & 0 & 0 & Distant flap \\
\hline Female & 46 & Banker & None & Married & $\begin{array}{l}\text { Lateral upper } \\
\text { alveolar process }\end{array}$ & 4 & 0 & 0 & Distant flap \\
\hline Male & 56 & Bricklayer & None & Not married & Lateral tongue & 2 & 0 & 0 & Local \\
\hline Male & 56 & Gardener & None & Not married & Cheek & 2 & 0 & 0 & Distant flap \\
\hline Male & 54 & Machinist & Evangelic & Married & Anterior mouth floor & 1 & 0 & 0 & Distant flap \\
\hline Female & 67 & Secretary & Catholic & Married & Lower lip & 1 & 0 & 0 & Local \\
\hline Female & 76 & Artist & None & Married & Lateral tongue & 1 & 0 & 0 & Local \\
\hline
\end{tabular}

1 month to 6 months postoperatively (RO MV 4.5 to MV 3.9). The global analysis showed a significant trend for all subscales (in particular: $\mathrm{RO}, \mathrm{P}<0.001$; $\mathrm{NP}, \mathrm{P}<0.001$; $\mathrm{AOL}, \mathrm{P}<0.001$; $\mathrm{SC}$, $\mathrm{P}=0.001$, and $\mathrm{PS}, \mathrm{P}<0.001)$. Pairwise comparisons revealed significant differences between PTG subscales. For RO, between 1 month and 1 year $(\mathrm{P}<0.0001)$ and 6 months and 1 year $(\mathrm{P}=0.024)$. For NP, between 1 month and 1 year $(\mathrm{P}<0.0001)$ and 6 months and 1 year $(\mathrm{P}=0.019)$. For $\mathrm{PS}$, between 1 month and 1 year $(\mathrm{P}<0.0001)$ and 6 months and 1 year $(\mathrm{P}=0.003)$. Also, significant differences could be observed between AOL subscale after 1 month and 1 year $(\mathrm{P}<0.0001)$ and 6 months and 1 year $(\mathrm{P}=0.002)$, and $\mathrm{SC}$ between 1 month and 1 year $(\mathrm{P}=0.006)$.

Analysis revealed slightly higher mean values in all five subscales for patients younger than 60 years of age $(\mathrm{MV}, 3.5)$ than those over 60 years (MV, 3.0). However, just for the 'new possibilities' subscale, the difference was statistically significant $(\mathrm{P}=0.040)$. A graphical representation is shown in Fig. 2B.

No significant correlation between PTG and sex or PTG and marital status has been found. The P-value from the 'relating to others' scale $(\mathrm{P}=0.04)$ indicates a significant correlation between the intensification of 'relating to others' and 'spiritual change.'

Correlation between HRQOL and PTG. Statistical analyses results revealed a significant negative correlation between physical and socio-emotional HRQOL and the PTG subscales, 'new possibilities', and 'appreciation of life' (all P-values $<0.05$ ). All other correlation tests were not significant, as depicted in Fig. 3.

\section{Discussion}

Head and neck cancers continue to be characterized by poor survival outcome and reduced HRQOL of patients $(21,22)$. However, life-threatening diseases, such as cancer, are possible traumas that can trigger PTG (17). Many factors, such as hope, optimism, carer, and coping, may influence HRQOL and PTG. In this study, we characterize the relationship between influencing clinical factors, HRQOL, and PTG after extensive surgical OSCC treatment, and focus on data analyzable with available clinical standard questionnaires.

As already described in literature (23), the present analysis results showed a reduced physical- and socio-emotional HRQOL in all patients with OSCC. Comparable results, also achieved with the UW-QoL v4 questionnaire, were described one year postoperatively in patients with oropharyngeal carcinoma by Biazevic et al (24).

Chewing, swallowing, and speech were found to be the significant factors responsible for reduced postoperative physical HRQOL in this study. Most likely, these results are mainly due to the extensive intraoral OSCC resection and are comparable to the evaluation of Villaret et al (25).

The comparison of patients with tumors classified as T1/T2 showed a better HRQOL in those with local plastic defect reconstruction than in patients who received free microvascular flap reconstruction. In this context, it is important to note that there are important differences between the extents of tumor infiltration. Depending on the location, different surgical and reconstructive strategies are necessary. Interestingly, more than $50 \%$ of patients rated their health-related and overall HRQOL as 'good' or 'satisfying,' suggesting that despite the 

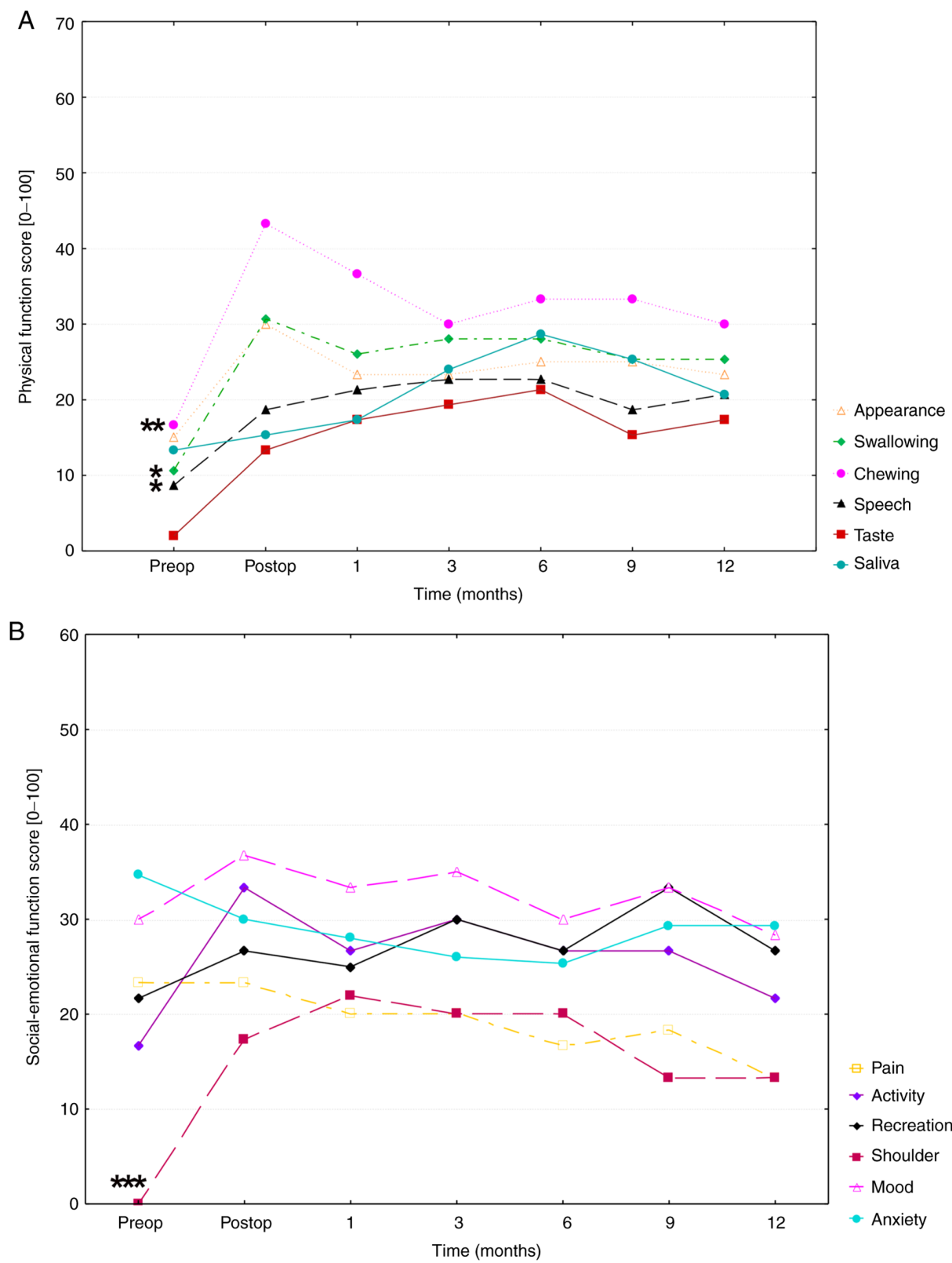

Figure 1. (A) Physical function score over time of the UW-QOL v4 questionnaire. The time of the mean scores of appearance, swallowing, chewing, speech, taste and saliva (physical subscales of the UW-QOL v4 questionnaire) are presented over a period from pre-surgery to 12 months post-surgery. High scores in the figure indicate poor HRQOL, whereas low scores indicate good HRQOL. (B) Social-emotional function score over time of the mean scores of pain, activity, shoulder, mood, anxiety and recreation (social-emotional subscales of the UW-QOL v4 questionnaire) over a period from pre-surgery to 12 months post-surgery. A Friedman test with Bonferroni-Dunn post hoc analysis was performed to compare differences between preoperative and mean postoperative physical and social-emotional function score values, respectively. Significances are indicated as asterisks $\left({ }^{*} \mathrm{P}<0.05,{ }^{* *} \mathrm{P}<0.01\right.$ and $\left.{ }^{* * *} \mathrm{P}<0.001\right)$. HRQOL, health-related quality of life. UW-QOL, University of Washington Quality of Life Version 4.

postoperatively reduced physical and socio-emotional function scores, the overall assessment was multifactorial influenced.

In this study, no sociodemographic factor, such as age, religion, and marital status, revealed a significant effect on HRQOL. This could be due to the small number of cases. Due to the burden of this dramatic life event, many patients who were preoperatively included in this trial showed poor postoperative compliance and were no longer willing to participate in the evaluation (drop-out rate, $\mathrm{n}=15$ ). However, the particular value of the recent study lies in the complete dataset with no missing values over the entire study period. This is an important difference from many other studies where data are incomplete. Men rated their HRQOL worse than women, which, however, was on borderline significance $(\mathrm{P}=0.058)$. The influence of sex on postoperative HRQOL is debatable. While Rogers et al (26) reported a better HRQOL in women, other studies did not demonstrate a significant difference between the sexes or report contrarily $(23,27)$.

Social support facilitates the coping process and reduces emotional discomfort. The ability to trust others and the feeling of support, understanding, and acceptance are considered important prerequisites for the emergence of PTG (19). The opportunity to express thoughts and fears gives patients the opportunity to complete mental processing $(28,29)$.

In this study, all patients with OSCC reported a postoperative PTG. PTG was most strongly felt immediately after 

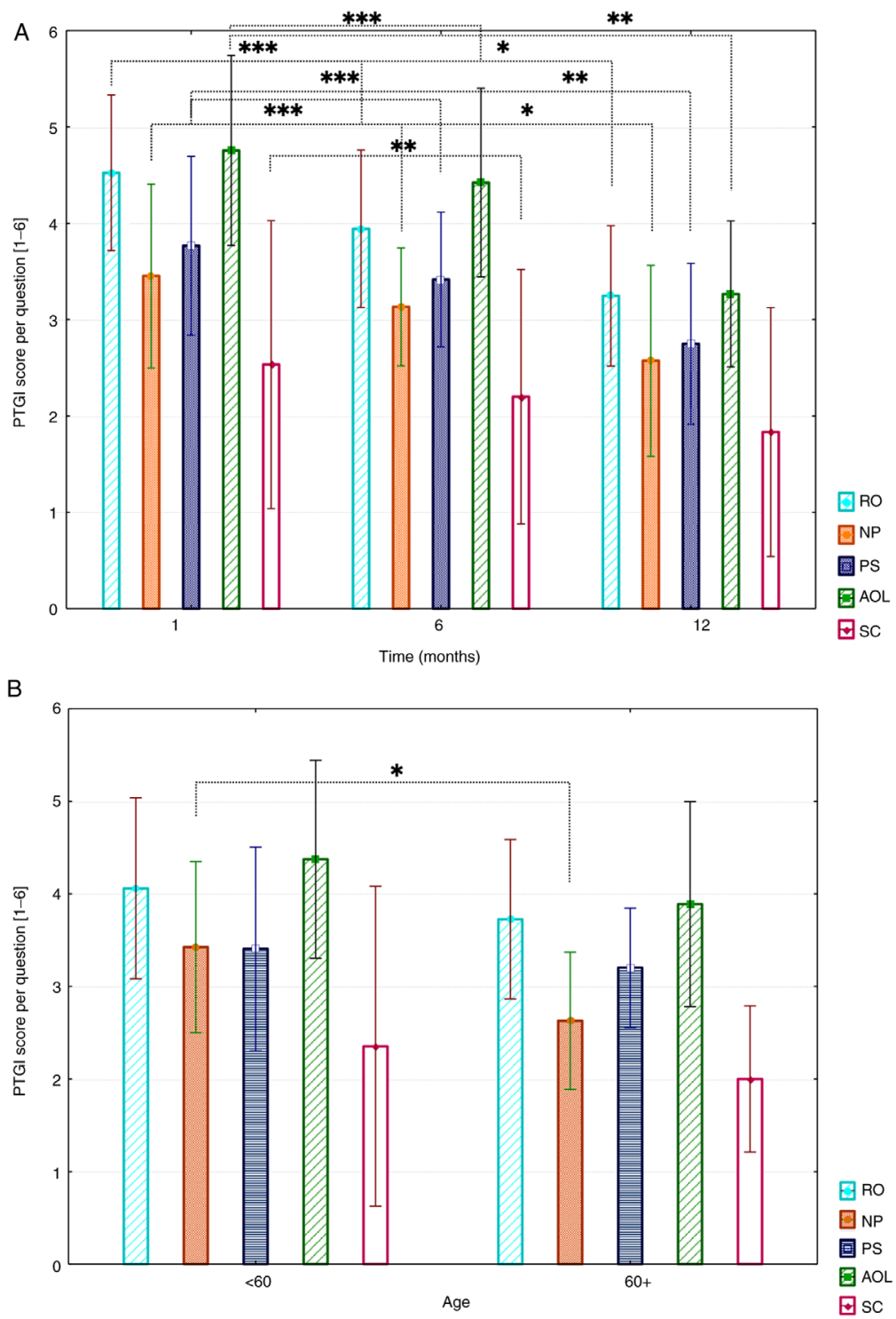

Figure 2. (A) Results of the PTGI questionnaire divided by subscales. MVs and SDs are demonstrated per question. A Friedman test with Bonferroni-Dunn post-hoc analysis was performed. $\mathrm{P}<0.05,{ }^{* *} \mathrm{P}<0.01$ and ${ }^{* * * *} \mathrm{P}<0.001$. (B) Influence of age on overall PTG (1-, 6- and 12-months), MVs and SDs are presented. A Mann-Whitney $\mathrm{U}$ test was performed to determine statistical significance. ${ }^{*} \mathrm{P}<0.05,{ }^{* *} \mathrm{P}<0.01$ and ${ }^{* * * *} \mathrm{P}<0.001$ as indicated. PTGI, Posttraumatic Growth Inventory; MV, mean values; RO, relating to others; NP, new possibilities; PS, personal strength; AOL, appreciation of life; SC, spiritual change.

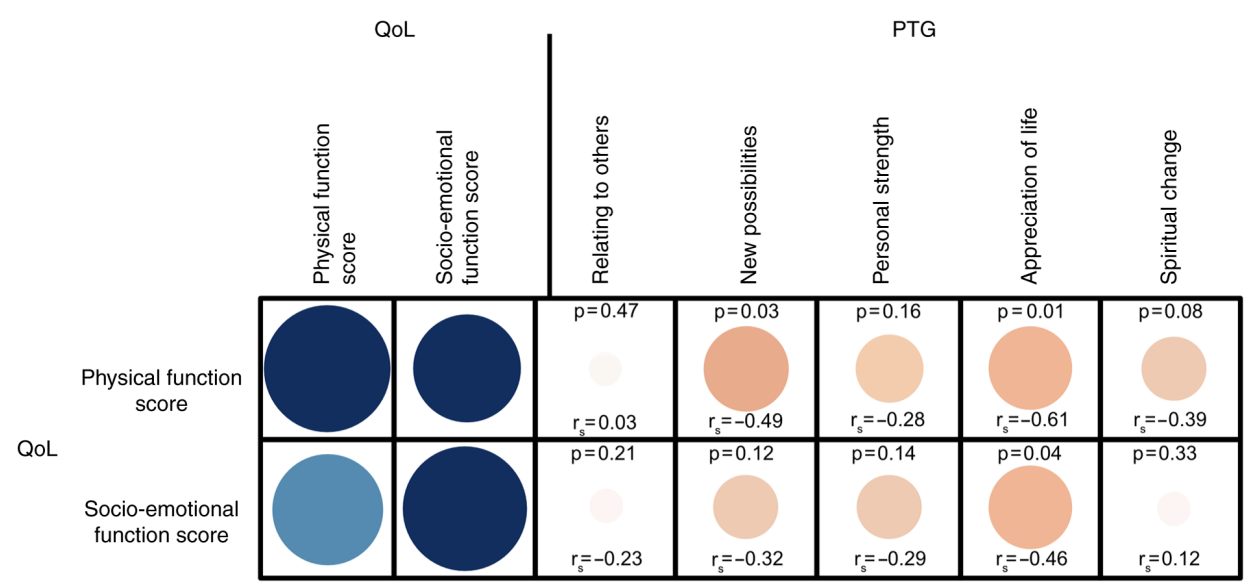

Figure 3. Correlogram presenting the correlation between HRQOL (social-emotional and physical function score) and all PTG subscales. The correlation strengths are illustrated in the form of size and color intensity. The correlogram is displayed with a color scale and shows a color gradient from blue (with scale 1), to white (with scale 0 ) to dark red (with scale-1). The size of the circle should additionally be an expression of the correlation strength. A Spearman's correlation analysis was performed to describe the relationship of HRQOL and PTG. P-value and Spearman's correlation coefficient $\left(\mathrm{r}_{\mathrm{s}}\right)$ are provided. HRQOL, health-related quality of life; QoL, quality of life; PTG, post-traumatic growth. 
treatment (one month) and decreased over the one-year study period. The data in the literature on the development of PTG in the follow-up interval are not definite (30).

Thus far, the PTG experience is unclear as to whether it is real or just a self-calming defensive illusion in the course of mental processing (31-33). The question of the objectivity of the subjectively perceived PTG has already been a focus of research and is still being discussed controversially $(34,35)$. In this context, the objectively collected PTGI values in this study should be noted to still indicate a positive perception even after one year. These results are consistent with those of the longitudinal study by Sharp et al (36). Additionally, the authors used the PTGI questionnaire by Tedeschi and Calhoun for PTG evaluation (17). 'Appreciation of life' had the highest mean value in this study, followed by the 'relating to others' and 'personal strength' subscales. In contrast to our results, however, 'spiritual change' occupied a stronger position among patients. The feeling of having 'new possibilities' was least felt by patients with head and neck cancers.

The findings of the study revealed slightly higher mean PTG values in all five subscales for younger patients than older patients. However, for the 'new possibilities' scale, the difference was statistically significant $(\mathrm{P}=0.040)$. Sharp et al (36) and others (37) reported similar results and assumed that older patients had a different perception due to earlier life experiences.

Although numerous studies have highlighted the effect of sociodemographic factors on PTG $(30,37)$, no significant correlation between PTG, sex, marital status, or religious affiliation could be observed in this study. Despite the lack of significance, women tended to show higher values in all five PTG subscales, as also described by others $(35,36,38,39)$. Although patients who identified themselves as non-denominational reported higher average values in three of the five subscales, spirituality did not show any significant effect on PTG in this study. In contrast, other studies reported that people with strong beliefs had less difficulty in coping with trauma $(39,40)$.

A higher level of psychological distress is generally assumed to correlate with a higher level of PTG (41). We found a significant negative correlation between HRQOL and PTG in patients with OSCC. Patients reporting a poor HRQOL also reported poorer PTG values. This is corroborated by other studies $(34,36,42)$. However, so far, no consistent relationship between HRQOL and PTG has been found (37).

After extensive tumor surgery, postoperative HRQOL and PTG are the most important factors for patients dealing with this traumatic life event. Many individually different factors can affect HRQOL and PTG, which can be assessed with available standardized questionnaires. Due to the suspicion of coherence in patients with OSCC, these should be used in clinical practice for postoperative combined screening to address individual patient needs and improve cancer follow-up care.

\section{Acknowledgements}

Not applicable.

\section{Funding}

No funding was received.

\section{Availability of data and materials}

The datasets used and/or analyzed during the current study are available from the corresponding author on reasonable request.

\section{Authors' contributions}

RMG and JJL conceived the current study. GH, JJL and BW collected all data. RMG and PB evaluated and interpreted all data and confirm the authenticity of all the raw data. GH, RMG and PB were major contributors in writing the manuscript. BS, PK made substantial contributions to the analysis and interpretation of data. HS made substantial contributions to the conception and design of the study and revised the manuscript. All authors read and approved the final manuscript.

\section{Ethics approval and consent to participate}

The study was conducted in accordance with the ethical standards (Declaration of Helsinki) approved by the local ethics committee of the University Medical Center Goettingen (approval no. 27/04/06 and DOK_93_2013). Informed consent for participation the trial was obtained from patients.

\section{Patient consent for publication}

All patients gave their consent for publication of patient data and associated images.

\section{Competing interests}

The authors declare that they have no competing interests.

\section{References}

1. Sung H, Ferlay J, Siegel RL, Laversanne M, Soerjomataram I, Jemal A and Bray F: Global cancer statistics 2020: GLOBOCAN estimates of incidence and mortality worldwide for 36 cancers in 185 countries. CA Cancer J Clin 71: 209-249, 2021.

2. Lo WL, Kao SY, Chi LY, Wong YK and Chang RC: Outcomes of oral squamous cell carcinoma in Taiwan after surgical therapy: Factors affecting survival. J Oral Maxillofac Surg 61: 751-758, 2003.

3. Howaldt HP, Vorast H, Blecher JC, Reicherts M and Kainz M: Results of the DOSAK tumor register. Mund Kiefer Gesichtschir 4 (Suppl 1): S216-S225, 2000 (In German).

4. Figuero Ruiz E, Carretero Pelaez MA, Cerero Lapiedra R, Esparza Gomez G and Moreno Lopez LA: Effects of the consumption of alcohol in the oral cavity: Relationship with oral cancer. Med Oral 9: 14-23, 2004 (In English, Spanish).

5. Ferrans CE: Quality of life: Conceptual issues. Semin Oncol Nurs 6: 248-254, 1990.

6. Morton RP and Izzard ME: Quality-of-life outcomes in head and neck cancer patients. World J Surg 27: 884-889, 2003.

7. Calman KC: Quality of life in cancer patients-an hypothesis. J Med Ethics 10: 124-127, 1984.

8. Han KT, Park EC, Kim JH, Kim SJ and Park S: Is marital status associated with quality of life? Health Qual Life Outcomes 12: 109,2014

9. Reis LB, Leles CR and Freire MC: Associations of religiosity and spiritual well-being with appearance concerns after head and neck cancer surgery. Community Dent Oral Epidemiol: Dec 28, 2020 (Epub ahead of print). doi: 10.1111/cdoe.12615.

10. Rogers SN, Fisher SE and Woolgar JA: A review of quality of life assessment in oral cancer. Int J Oral Maxillofac Surg 28: 99-117, 1999. 
11. Rathod S, Livergant J, Klein J, Witterick I and Ringash J: A systematic review of quality of life in head and neck cancer treated with surgery with or without adjuvant treatment. Oral Oncol 51: 888-900, 2015.

12. Pusic A, Liu JC, Chen CM, Cano S, Davidge K, Klassen A, Branski R, Patel S, Kraus D and Cordeiro PG: A systematic review of patient-reported outcome measures in head and neck cancer surgery. Otolaryngol Head Neck Surg 136: 525-535, 2007.

13. Rogers SN, Ahad SA and Murphy AP: A structured review and theme analysis of papers published on 'quality of life' in head and neck cancer: 2000-2005. Oral Oncol 43: 843-868, 2007.

14. Rogers SN, Lowe D, Yueh B and Weymuller EA Jr: The physical function and social-emotional function subscales of the university of washington quality of life questionnaire. Arch Otolaryngol Head Neck Surg 136: 352-357, 2010.

15. Moschopoulou E, Hutchison I, Bhui K and Korszun A: Post-traumatic stress in head and neck cancer survivors and their partners. Support Care Cancer 26: 3003-3011, 2018.

16. Shakespeare-Finch J and Lurie-Beck J: A meta-analytic clarification of the relationship between posttraumatic growth and symptoms of posttraumatic distress disorder. J Anxiety Disord 28: 223-229, 2014.

17. Tedeschi RG and Calhoun LG: Posttraumatic Growth: Conceptual foundations and empirical evidence. Psychol Inquiry 15: 1-18, 2004

18. Harding S, Sanipour F and Moss T: Existence of benefit finding and posttraumatic growth in people treated for head and neck cancer: A systematic review. PeerJ 2: e256, 2014.

19. Tedeschi RG and Calhoun LG: The posttraumatic growth inventory: Measuring the positive legacy of trauma. J Trauma Stress 9: 455-471, 1996.

20. Maercker A and Langner R: Persönliche Reifung (Personal Growth) durch Belastungen und Traumata. Diagnostica 47: 153-162, 2001.

21. So WK, Chan RJ, Chan DN, Hughes BG, Chair SY, Choi KC and Chan CW: Quality-of-life among head and neck cancer survivors at one year after treatment-a systematic review. Eur J Cancer 48: 2391-2408, 2012

22. Borggreven PA, Verdonck-de Leeuw IM,Muller MJ,Heiligers ML, de Bree R, Aaronson NK and Leemans CR: Quality of life and functional status in patients with cancer of the oral cavity and oropharynx: Pretreatment values of a prospective study. Eur Arch Otorhinolaryngol 264: 651-657, 2007.

23. Schliephake $\mathrm{H}$ and Jamil MU: Prospective evaluation of quality of life after oncologic surgery for oral cancer. Int J Oral Maxillofac Surg 31: 427-433, 2002.

24. Biazevic MG, Antunes JL, Togni J, de Andrade FP, de Carvalho MB and Wunsch-Filho V: Survival and quality of life of patients with oral and oropharyngeal cancer at 1-year follow-up of tumor resection. J Appl Oral Sci 18: 279-284, 2010

25. Villaret AB, Cappiello J, Piazza C, Pedruzzi B and Nicolai P: Quality of life in patients treated for cancer of the oral cavity requiring reconstruction: A prospective study. Acta Otorhinolaryngol Ital 28: 120-125, 2008.

26. Rogers SN, Humphris G, Lowe D, Brown JS and Vaughan ED: The impact of surgery for oral cancer on quality of life as measured by the Medical Outcomes Short Form 36. Oral Oncol 34: 171-179, 1998.

27. Vartanian JG, Carvalho AL, Yueh B, Priante AV, de Melo RL, Correia LM, Köhler HF, Toyota J, Kowalski IS and Kowalski LP: Long-term quality-of-life evaluation after head and neck cancer treatment in a developing country. Arch Otolaryngol Head Neck Surg 130: 1209-1213, 2004.
28. Lepore SJ, Silver RC, Wortman CB and Wayment HA: Social constraints, intrusive thoughts, and depressive symptoms among bereaved mothers. J Pers Soc Psychol 70: 271-282, 1996.

29. Vishnevsky T, Cann A, Calhoun LG, Tedeschi RG and Demakis GJ: Gender differences in self-reported posttraumatic growth: A meta-analysis. Psychology Women Qrterly 34: $110-120,2010$.

30. Casellas-Grau A, Ochoa C and Ruini C: Psychological and clinical correlates of posttraumatic growth in cancer: A systematic and critical review. Psychooncology 26: 2007-2018, 2017.

31. Zoellner T and Maercker A: Posttraumatic growth in clinical psychology-a critical review and introduction of a two component model. Clin Psychol Rev 26: 626-653, 2006.

32. Ho S, Rajandram RK, Chan N, Samman N, McGrath C and Zwahlen RA: The roles of hope and optimism on posttraumatic growth in oral cavity cancer patients. Oral Oncol 47: 121-124, 2011.

33. Rajandram RK, Jenewein J, McGrath C and Zwahlen RA: Coping processes relevant to posttraumatic growth: An evidence-based review. Support Care Cancer 19: 583-589, 2011.

34. Menger F, Patterson J, O'Hara J and Sharp L: Research priorities on post-traumatic growth: Where next for the benefit of cancer survivors? Psychooncology 29: 1968-1970, 2020.

35. McFarland C and Alvaro C: The impact of motivation on temporal comparisons: Coping with traumatic events by perceiving personal growth. J Pers Soc Psychol 79: 327-343, 2000.

36. Sharp L, Redfearn D, Timmons A, Balfe M and Patterson J: Posttraumatic growth in head and neck cancer survivors: Is it possible and what are the correlates? Psychooncology 27: 1517-1523, 2018.

37. Shand LK, Cowlishaw S, Brooker JE, Burney $S$ and Ricciardelli LA: Correlates of post-traumatic stress symptoms and growth in cancer patients: A systematic review and meta-analysis. Psychooncology 24: 624-634, 2015

38. Ruf M, Buchi S, Moergeli H, Zwahlen RA and Jenewein J: Positive personal changes in the aftermath of head and neck cancer diagnosis: A qualitative study in patients and their spouses. Head Neck 31: 513-520, 2009.

39. Linley PA and Joseph S: Positive change following trauma and adversity: A review. J Trauma Stress 17: 11-21, 2004.

40. Schreiber JA and Brockopp DY: Twenty-five years later-what do we know about religion/spirituality and psychological well-being among breast cancer survivors? A systematic review. J Cancer Surviv 6: 82-94, 2012

41. Tomich PL and Helgeson VS: Posttraumatic growth following cancer: Links to quality of life. J Trauma Stress 25: 567-573, 2012.

42. Sim BY, Lee YW, Kim H and Kim SH: Post-traumatic growth in stomach cancer survivors: Prevalence, correlates and relationship with health-related quality of life. Eur J Oncol Nurs 19: 230-236, 2015.

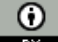

This work is licensed under a Creative Commons Attribution 4.0 International (CC BY 4.0) License. 